\title{
ARTIG0S
}

\author{
AS IDÉIAS POLÍTICAS DE BOLIVAR (1).
}

\section{Considerações gerais.}

A apreensão das idéias políticas de Bolviar por sua própria natureza apresenta uma série de "handicaps" ao historiador. Bolivar pertence à raça dos Robespierre, Lincoln e Napoleão, àquêles que deduziram suas idéias políticas partindo de premissas políticomilitares definidas. A idéia tem um sentido operativo, ela se liga à necessidades da urgência da ação politica.

Nesse sentido, como Robespierre, Lincoln ou Napoleão, Bolivar é um pensador asistemático. Sua coerência ideológica se situa em função da luta revolucionária pela libertação das Américas contra o' domínio do colonialismo espanhol. Nesse sentido, é difícil ao historiador abstrair as idéias políticas de seu contexto empírico, sem trair a intenção de seu autor.

Isso é tanto mais difícil mormente em homens que forjaram por assim dizer "existencialmente" seu universo ideológico. Daí existir certa indefinição fronteiriça entre teoria e prática em Bolivar que o historiador deve considerar sob pena de trair o sentido da obra do caudilho.

Em que medida Bolivar é o pensador político, em que medida é o estrategista da luta emancipadora, em que medida é o grande político panamericano? A delimitação lógica de fronteiras é perigosa, nesse sentido cabe uma delimitação operativa, abstraise como hipótese de trabalho suas idéias políticas no sentido genético, na medida em que os grandes pensadores influiram em sua ação, e no seu sentido operativo, em que medida suas idéias determinaram a ação política concreta.

Sempre que necesșário deverá o historiador recorrer a exemplos empíricos no sentido de esclarecer o universo do pensamento político bolivariano nos dois sentidos: genético e seu grau operativo determinados elementos empíricos indispensáveis à perfeita compreensão do problema.

Acresce notar que a coerência política do caudilho se formou na base de uma experiência histórica que toma uma forma clara na Carta de Jamaica (1815), se desenvolve no Congresso Consti-

(1). - Trabalho laureado pelo "Pen Clube Internacional" com o "Prêmio Carnar vali", destinado a universitários alunos da cátedra de História da América (Nota da Redação). 
tucional de Angostura (1819), atingindo seu ápice no Congresso do Panamá (1826), é no decurso da experiência empítica que Bolivar deduz seu universo ideológico.

Ao historiador que procura não cair no chamado sistema "idealista" ou "atitude idealista" na história, o elemento empírico é fundamental para o estabelecimento de séries de desenvolvimento ideológico que conduzam à estruturação de um sistema orgânico político.

Bolivar conseguiu construir um sistema orgânico-político partindo da indeterminação de suas primeiras experiências empíricas. Nesse sentido a crítica de Madariaga no seu "Bolivar" peca por $\epsilon \mathrm{x}$ cessiva falta de simpatia e determinados preconceitos de ordem afetiva transpostos à análise histórica.

Em história, seguimos o dito espinozista "nem rim nem chorar, importa compreender". Pelo fato justamente de Bolivar ter fundamentado suas idéias no decurso de sua luta pela independência é que elas tem um fundamento autêntico, existencial que nenhum estudioso pode descurar. Seu projeto de vida não era se realizar como intelectual, teórico, mas como revolucionário que utilizava as idéias como o fazia com as armas: aniquilava o inimigo.

No presente trabalho procuramos caracterizar os traços fundamentais da dominação espanhola nas Américas, a evolução do processo de insurreição contra essa dominação, as influências européias no pensamento bolivariano; suas diversas atitudes referentes à religião, filosofia. Sua ação política significativa donde partiu uma primeira esquematização de seu pensamento político; finalizando com - Congresso do Panamá.

*

Traços gerais da dominação espanhola.

Os povos crioulos das Américas constituem-se predominantemente de povos selvagens em estágio primitivo de organização social, assim são as monarquias bárbaras dos chibchas na Colômbia, incas no Perú e aztecas no México. Nessa condição êsses povos sofrem o contacto de uma cultura européia, onde conquistadores espanhóis e portuguêses fanáticos deixam uma Espanha e Portugal arruinados para encontrar uma América cheia de ouro.

A Europa vivia no mercantilismo, a procura do ouro se situa na ordem do dia. E é o ouro retirado da América Espanhola, como posteriormente das Minas Gerais brasileiras, que fecundará o processo de entesouramento mercantilista europeu, criando posteriormente uma baixa de preços, conforme a tese do historiador norteamericano Earl Hamilton, que permitirá a eclosão da revolução industrial. 
Nas regiões da América espanhola, onde não existem zonas de exploração auríferas, forma-se uma sociedade latifundiária.

Nessa sociedade colonial o status é definido pela côr da pele, o govêrno é absolutista, reina o monopólio financeiro. Carlos V e Filipe II, fiéis ao espírito do colonialismo da época, impõem às Américas uma reclusão conventual que as transforma numa autarquia econômica, cujo fim é a extração do ouro. Nessa autarquia a Igreja ocupa um papel central na estratificação social da Colônia.

O documento que caracteriza em seus aspectos significativos a estrutura da sociedade colonial sob domínio espanhol é a carta de Bolivar dirigida a um inglês da Jamaica, datada de janeiro de 1815:

"Dentro do sistema espanhol que domina hoje mais dó que nunca só nos é permitido o oficio de servos para o trabalho ou simples consumidores, mas com restrições chocantes, como por exemplo, proibição de cultivar frutos da Europa, monopólios dos muitos produtos que temos que reservar ao Rei, interdição do estabelecimento de fábricas, mesmo aquelas que não existem nas metrópoles. Direitos excessivos sôtre as mercadorias e sôbre os objetos de primeira necessidade; entraves de todo o gênero para que não possam entender-se entre si as potências americanas. Numa palavra, quereis saber a que nos destinavam? Aos campos para cultivar os cereais, o café, o algodão, o cacau; às planícies solitárias para cuidar dos rebanhos, para extrair o ouro que a Espanha ambicionava. Em síntese, ao cultivo de raizes raras e frutos tropicais" (2) .

\section{Primeiros movimentos revolucionários.}

E' justamente contra êsse tipo de limitações que se cria no México a Sociedade dos Guadalupes e registram-se a insurreição dos Comuneros de Corrientes (1762) no Paraguai, o levante de Catari e a rebelião de Tupac Amaru (1780). E' todo um ciclo de rebeliões que põem em cheque a dominação espanhola e que possuem um caráter crioulo, nativista.

No seu início tais movimentos mantém uma relação feudal de fidelidade a Fernando VII, nesse sentido se pronunciam: a primeira Junta criada em 1809, o Cabildo de Buenos Aires, a Junta Tuiutiva de La Paz e a Revolta de Quito. Tal relação de fidelidade a Fernando VII se desfaz quando o monarca resolve dissolver as Côrtes liberais de Cádiz criando em seu lugar um govêrno despótico. Isso acelera a velocidade do movimento autonomista.

(2). - Cf. PABLO DE ROCHA, Interpretacion disletica de America. Ed. Claridad, 1947, Buenos Aires, pp. 340-341. 
Assim

"Na Venezuela quando em Caracas é deposto o representante espanhol e constituída em 1810 uma Junta Conservadora dos Direitos de Fernando VII, o cônego Madariaga "pregador favorito do povo" inflama todos com seu verbo, exige a deposição do Governador espanhol "e o estabelecimento de um Govêrno composto ünicamente de Americancs" (3).

Nessa luta a influência francesa manifesta-se em tôda a sua amplitude, isso é atestado pela declaração de Napoleão em 12 de novembro de 1809 na Câmara Francesa:

"A independência das nações americanas está na ordem necessária dos acontecimentos".

Mas essa influência foi perceptível mais no México, Norte da América do Sul, Antilhas e América Central, devido a proximidade das possessões francesas sublevadas naquela época, como São Domingos, por exemplo.

$\mathrm{O}$ espírito autonomista liga-se necessàriamente à uma visão liberal.

"Já em 1797 na rebelião de Caracas, as zelosas autoridades atribuem a êsse movimento a difusão de obras heréticas que estabeleciam proposições capazes de conduzirem à rebelião e à anarquia" (4).

De fato, tais obras penetram nas Américas convertendo as Universidades americanas em focos de agitação revolucionária.

Em 1794, no México, é prêso Frei Juan Francisco Ramirez por distribuir livros proibidos, especialmente Voltaire, D'Alembert, Rousseau, adquiridas por êle dois anos antes em Sevilha de um comerciante francês. No Uruguai o Governador Elro

"denuncia em 1811 a propaganda feita pelos conventos de dominicanos, sobretudo, franciscanos" (5).

$\mathrm{Na}$ Guatemala, em 1795, verifica-se uma onda de perseguição ao elemento estrangeiro, principalmente aos franceses e maçons, não conseguindo deter a difusão de livros proibidos.

As obras da Ilustração influenciaram os grandes líderes sulamericanos $\mathrm{e}$

"Belgrano, Moreno, Monteagudo reconhecem que a França exerceu uma influência decisiva na formação de suas idéias emancipadoras" (6) .

(3). - OLIMPIO GUILERME, A Luta pela liberdade nas Américas, Ed. José Olympio. Rio de Janeiro, 1945, p. 279.

(4). - Ibidem, p. 277

(5). - Ibidem, p. 280

(6). - LUIZ ALBERTo SANCHEZ, Historia de America, p. 41. 
Ao liberalismo político liga-se a ideologia do liberalismo econômico, desenvolvida pela Escola Clássica.

"Adam Smith e Bentham fizeram cair as teorias mercantilistas segundo às quais as colônias devem fornecer apenas matérias primas e clientes exclusivos dos produtos manufaturados pelas respectivas metrópoles, tem como pedra de toque de todos os absolutismos, segundo o qual, o poder emana de outras fontes que nẫo o consentimento dos governados" (7) .

À vitória da Escola Clássica e à derrota do mercantilismo econômico correspondem o desenvolvimento do capitalismo industrial, do liberalismo político e lògicamente dos intuitos emancipadores das colônias oprimidas pelo imperialismo "fiscalista" do mercantilismo.

As inferências políticas da vitória da Escola Clássica são que todo poder emana do povo, a legitimidade tradicional do poder absoluto cai por terra.

"A revolução francesa transfere a soberania do monarca tido como encarnação do país ao país mesmo e por outro lado, roda a Corôa da Espanha no arrôio pelo formidável empurrão de Napoleão. Esses dois sucessos fomentaram nas Espanhas de ultramar o espirito republicano" (8).

Liberalismo econômico, liberdade política, legitimidade popular do poder, luta contra o colonialismo e o absolutismo, é nesse quadro que se encarna a ação e pensamento político de Simon Bolivar.

A construção das idéias politicas de Bolivar.

O pensamento político de Bolivar tem como traço básico ser asistemático.

"Suspeitamos pois nele tendências a coisas profundas da vida, tão complexa como os demais aspectos de um ser tão heterogêneo. Tanto mais por êle não ser um pensador, senão um homem de ação. Sua tendência natural não o levava à uma imagem clara e coerente do mundo como sistema, senão que se dirigia d vida impondo-lhe o sinete de sua dominante e imperiosa personalidade" (9).

Era maçon desde os 20 anos (10), correspondia-se com Bentham (11), afeiçoado a Voltaire (12), onde

\footnotetext{
(7). - OLIMPIO GUILERME, ob. cit., p. 268.

(8). - SALVADOR DE MADARIAGA, Bolivar, vol. II, p. 131.

(9). - Ibidem, vol. I, p. 170.

(10). - OLIMPIO GUILERME, ob. cit., p. 281 .

(11). - Ibideml p. 285.

(12). - SALVADOR DE MADARIAGA, ob. cit., p. 176.
} 
"encontra estilo, grandes e profundos pensamentos, filosofia, crítica fina e diversões" (12a).

Admirador do

"Diário de Santa Helena onde encontra ensinamentos sôbre a arte da guerra, da política, do govêrno" (13).

conhecedor de Rousseau onde

"Ieu o Contrato Social num exemplar que pertenceu à biblioteca de Napoleão, que legou a um amigo intimo por testamento" (14). .

discípulo de Montesquieu,
"não diz o Espírito das leis que essas (as idéias) de- vem ser próprias aos governos que as fazem?" (15).

com todos êsses elementos ideológicos Bolivar se dispôs à traduzí-los em atos: utilizá-los na luta contra a dominação espanhola.

No entanto é mister considerar que o pensamento de Bolivar era tão heterogêneo como o resto de seu caráter (16).

Ao seu liberalismo político temperado com leituras de Rousseau, Montesquieu e Voltaire, influenciado pelo utilitarismo de Bentham, com quem teve correspondência e que numa carta aponta os remédios contra possíveis atentados que venha a sofrer, escrevendo,

“contra tais perigos, o preservativo mais eficaz é dar de fato e de direito uma base sólida e consistente à forma de govêrno que professar, ter por objeto a felicidade ao maior número" (17).

teve Bolivar uma atitude tìpicamente racionalista ante a religião, isso em profunda conexão com seu liberalismo político.

"Em seus moméntos de consciência era materialista e racionalista. Não gosto de entrar em metafísicas que estão em bases falsas. Basta-me saber e estar convencido que a alma tem a faculdade de sentir, isso é, receber impressões de nossos sentidos, mas não tem a faculdade de pensar, porque não admito idéias inatas... $O$ homem tem um corpo material e segundo o estado atual da ciência não se considera a inteligència senão uma secreção do cérebro, chame-se a êsse produto alma, inteligência, es-

\footnotetext{
(12a). - Cf. DIÁrio DE BUCAMARANGA, de Peru de Lacroix, Avila Grafica. 1949. Caracas, dia 23 de maio de 1828, pp. 102-103.

(15). - v. $\mathrm{v}$. LECUNA em Prólogo á Simon Bolivar. Ideas Militares y Politicas, Buenos Aires, 1945, p. XXV. Ed. Jackson.

(16). - SALVADOR DE MADARIAGA, ob. cit., vol. I, p. 174

(17). - J. BENTEAM, Carta de Londres, em 13 de agôsto de 1825 para Bolivar in Manuel Perez Villa, Bolivar y su epoca, vol. I, p. 222.
} 
pírito, pouco me importa, nem vale a pena discutir sôbre isso. Para mim, a vida não é outra coisa senão a união de dois principios, a fusão que é uma faculdade do corpo material e a sensibilidade que é uma faculdade do cérebro. Cessa a vida quando cessa a união, o cérebro morre com o corpo e morto o cérebro não há mais secreção de inteligência.

o tempo, a instrução, a filosofia e uma certa disposição na inteligência vão pouco a pouco iniciando os camponeses nas ciências naturais, tirando-lhes a preferência pelos sobrenaturais" (18).

Lògicamente que uma formação racionalista dêste tipo veria com olhos críticos o pensamento e ação da Igreja Católica, mormente pelo seu papel histórico tender à centralizar em tôrno de si a vida da Colônia.

"Nem posso lembrar-me sem riso e desprêzo o édito com que excomungou a mim e a todo exército o arcebispado de Bogotá. Dres. Prey e Duquesne em 13 de dezembro de 1814 , tomando por pretexto que eu me propunha saquear as igrejas, violar virgens, degolar homens e crianças e tudo isso para retratá-lo com outro édito quee em lugar de pintar-me como um impio e herege confessava que eu era um bom e fiel católico. Que farsa tão ridícula e que lição para os povos! Nove ou dez dias teve o édito de intervalo" (19).

E' possível encontrarem-se raizes dessa oposição à Igreja Católica em sua formação maçônica, no entanto, sua atitude ante a religião estava determinada por suas finalidades politicas. Nesse sentido

"no estado de civilização da Colômbia, do fanatismo e preocupações religiosas em que estão seus povos não era político valer-se da maçonaria, pois, ter alguns partidários nas lojas atrairia o ódio e a censura de tôda nação movida contra ela pelo clero e os frades que se valem dêsse pretexto, teria pouco a ganhar na maconaria e muito a perder ante a opiniâo pública" (20).

Sua atitude ante a Igreja era de um racionalista igualmente ante seu papel político, conhecia suas limitações temporais, sabia ser um instrumento de que se vale a história para se realizar a si própria.

"Eu não fui o único autor da revolução, durante a crise revolucionária e a longa luta entre as tropas espanholas e patriotas não deixaria de aparecer algum caudilho se eu nâo me houvesse apresentado e a atmosfera

(18). - DIARIO, 17 de maio de 1828, p. 89.

(19). - Ibidem, p. 161 .

(20). - Ibidem, p. 69 . 
de minha fortuna não houvesse como impedido a junção de outros, mantendo-os numa esfera sempre inferior à minha. Deixemos os supersticiosos acreditarem que a Providência é que me ou me destinou a redimirl a Colômbia, as circunstâncias, o' meu caráter, o gênio, minhas paixôes ine colocaram nesse caminho" (21).

Sua atitude racionalista ante sua função histórica como homem aparece também na crença que um ajustamento racional de personalidades seria o suficiente para fundamentar uma determinada ordem política.

"Se pelo contrário (referindo-se a seus opositores), êles houvessem caminhado em união comigo, de boa fé, a República, seu govêrno e suas instituições estariam assentados sôbre um rochedo e ninguém poderia sequer abalá-lo, os povos seriam livres e felizes porque com a tranqüilidade interior e a confiança tudo progrediria até a ilustração e com ela o liberalismo e a verdadeira liberdade" (22) .

Sua formação racionalista e liberal transparece quando à vista da realidade concreta das Américas que impunha uma ditadura, êle por sua formação ideológica se recusa a cumprir tal papel.

"Com os elementos morais que há no país, com nossa educação, nossos vicios e costumes, só sendo um tirano, um déspota, poderia governar bem a Colômbia, mas não o sou e nunca o serei, ainda que meus inimigos assim me intitulem, minha vida pública não oferece nenhum fato que a comprove. O escritor imparcial que escrever minha história ou da Colômbia, dirá que fui ditador, chefe supremo nomeado pelos povos, mas não um tirano, um déspota" (23) .

As idéias políticas de Bolivar, como acentuamos anteriormente, se estruturam em dois planos: o plano genético, o nascimento de suas idéias políticas ligada à experiência européia, ao espírito da Ilustração, o plano operativo, a aplicação e validade dessas mesmas idèias numa conjuntura histórica determinada: a situação das Américas na luta revolucionária contra o poder espanhol. As idéias políticas de Bolivar se criam e recriam à luz da "praxis" político-militar.

Em linhas gerais, a ação política de Bolivar pode ser definida em:

1. Propaganda revolucionária anti-espanhola. Destruição do velho regime e ruptura definitiva com a Espanha.

(21). - Ibidem, pp. 63 a 65. Em 10 de maio de 1828

(22). - lbidem, p. 29,2 de maio de 1828 .

(23), - Ibidem, p. 34, em. 3 de maio de 1828 . 
2. Criação de um govêrno estável e unitário para vencer o conflito.

3. Congresso do Panamá, união das Américas.

Em 1810 foi Bolivar a Londres explicar à Inglaterra as vantagens do comércio livre que sucederia à derrubada do Império Espanhol. Em 1790 ela havia auxiliado Miranda, fornecendo-lhe uma frota e um almirante: Cochrane (24).

Ao ser invadida a Espanha pela França em 1823 para a reposição de Fernando VII, Canning procura evitar a influência francoespanhola, declarando na Câmara dos Comuns:

"Eu decidi que a França teria a Espanha sem as fndias (Américas). Olhei para a América com a finalidade de corrigir as desigualdades na Europa. Chamei o Novo Mundo à vida para restabelecer o eqüilibrio do antigo (I called the New World into existence, to redre'ss the balance of the old)" (25).

A propaganda anti-espanhola, o auxílio franco-inglês, no sentido ideológico ou material, criaram condições à vitória da revolução das Américas contra o Império Espanhol.

A bem da verdade é mister dizer que

"as nações européias aproveitaram a desarticulação latino-americana para penetrar profundamente em sua economia e em sua política subordinando-a à sua própria expansão mundial" (26) .

Após as vitórias de Carabobo (1821), Bambona e Pichincha (1823), Junin e Ayacucho (1824) o poderio espanhol está nos seus estertores, coloca-se na ordem do dia, um item básico: criação de um govêrno e comandos unitários para a vitória definitiva.

"Restabelecida assim a calma e a tranqüilidade podemos aproveitar os instantes concedidos ao descanso de nossas tropas para melhor consolidar nossas instituições, fixar um centro de govêrno, dar-lhe todo o vi. gor que necessita e pô-lo à salvo de tôdas as vicissitudes da revolução e da guerra. Era indispensável para isso uma instituição absolutamente nova em política, um Conselho de Estado composto dos principais chefes do Exército e dos funcionários públicos. A êle cabe a iniciativa das leis, regulamentos e estatutos que julgue conveniente no estado atual da nossa recente república" (27) .

(24) . - OLfMPIO GUILERME, ob. cit., p. 286.

(25). - Ibidem, p. 287.

(26). - JORGE ABELARDo RAMOS, America Latina un país, Ed. Octubre. Buede 1817. Doc, 41, citado por Salvador de Madariaga, Bolivar, vol. II.

(27). - Ofício de Bolivar à Lopez Mendez, de Pôrto do Pampatar em 25 de abril de 1817. Doc. 41, citado por Salvador de Madariaga, Bolivar, vol. II. 
A aplicação dos princípios acima enunciados seria a organização de uma república conservadora administrada por uma elite intelectual e moral.

Deseja êle formar uma vasta entidade nacional de diferentes nações, um govêrno baseado num conjunto semi-federal, semi-democrático, onde se verifica uma evidente influência napoleônica.

"A visão de Bolivar era audaz e profunda. Compreendeu mais profundamente que Miranda e incomparàvelmente mais que San Martin que a emancipação da América Latina seria alcançada através da unificação nacional de tôdas as partes do antigo Império colonial espanhol"' (28).

Bolivar bate-se fundamentalmente pelo nacionalismo, republicanismo, congresso independente, independência do Poder Judiciário e solidariedade continental.

A mola de sua ação política está no respeito à vontade popular.

“Eu não devo agir por mim ou para mim. Minha posição pública é a consciência de minhas atitudes públicas. Por isso não sei o que fazer nesse Alto Perú, porque a vontade legal do povo é seu soberano e minha lei. Quando os corpos legislativos decidirem a sorte do Alto Perú, eu saberei então qual é o meu dever e qual a marcha que farei" (29).

Não é na Carta de Jamaica (1815), Projeto Constitucional de Angostura (1819), mas sim na Constituição Boliviana (1825) que se encontram sistematizadas completamente as linhas mestras do pensamento político de Bolivar, de sua concepção de Estado, divisão de poderes, suas relações mútuas, etc.

Bolivar esboça um govêrno popular e representativo. O poder é dividido em três elementos: eleitoral, legislativo, executivo e judicial. Direito de voto secreto e universal.

Poder eleitoral - Cada 10 cidadãos nomeiam um eleitor. O poder eleitoral nomeava os membros às Câmaras Legislativas. Propunha ao Executivo os candidatos às principais magistraturas dos Departamentos e Províncias e os funcionários subalternos. Nomeava os membros das côrtes judiciais e dos tribunais e indicava ao Executivo os padres e vigários para preenchimento dos cargos.

Senadores - Formulavam os códigos e regulamentos eclesiásticos, escolhiam os juízes distritais. Possuiam mandato por 8 anos, dividido em duas metades de quatro anos.

(28). - JORGE ABELARDO RAMOS, ob. cit., p. 59.

(29). - Florence Daniel O'Leary, Bolivar y las Republicas del Sur. Ed. America. Madrí, 1919, p. 32 . 
Censores - Zelavam pelo cumprimento da Constituição e tratados públicos, protegiam a liberdade de imprensa e demais direitos assegurados pela Constituição. Eram vitalícios.

Presidente - Vitalício, possuia um número de funções correspondentes à igual cargo na República dos Estados Unidos.

Vice-Presidente - Hereditário. Isso visava eliminar as lutas pelo poder supremo. Era proposto às Câmaras pelo Presidente.

Poder Judiciário - Absolutamente independente do Executivo.

Tribunos - Votavam o orçamento anual, o número das fôrças armadas em serviço. Eram eleitos por 4 anos, em metades de 2 anos.

Secretários - Havia 3 (três) secretários de Estado, elementos de confiança do Presidente e escolhidos por êle.

A Constituição garantia ampla liberdade de imprensa, locomoção, não reconhecia privilégios de nascimento, garantia a igualdade perante a lei.

No intuito de garantir ampla liberdade de eleição da Assembléia, Bolivar toma medidas militares nesse sentido:

"O lugar da Assembléia deve estar longe a 20 léguas do Exército libertador. Nenhum militar estará no âmbito assinalado. Um juiz civil mandará no lugar e lógicamente você estará o mais longe que puller. Você proclamará aos povos dizendo-lhes estritamente que eu não visitarei essas províncias enquanto as sessões não tiverem terminado, que tais sessões não são mais que puramente deliberativas, que não terão nenhum efeito atual enquanto o Congresso do Perú não houver determinado o que o Libertador e o Exército Unido devem executar em relação às citadas provincias; que a assembléia se reunirá num local no qual não haverá um só individuo do exército libertador à distância de 20 léguas para impedir qualquer acusação de influência militar na decisão de seus representantes" (30).

Dentro dêsse espírito liberal é que a Assembléia do Alto Perú, reunida em Chuquisaia a 10 de julho, implorou a proteção do Libertador.

Simon Bolivar não teve como centro de preocupações problemas meramente políticos, para a justa compreensão do alcance de seu liberalismo político é mister enunciar algumas atitudes do Libertador no terreno econômico. 
Ele se esmerou em eqüilibrar o orçamento conseguindo-o por meio de um rígida política econômica. Com tal propósito estendeu à Bolívia os decretos que expediu no Perú declarando propriedade do Estado as minas que já estavam em exploração ou abandonadas por seus donos um ano e um dia vendendo-as em leilão; apesar das vantajosas ofertas de compra, não acreditou intimamente estar cumprindo seu dever para com o país, dispondo das minas sem prévia declaração das finalidades do govêrno e também porque esperava conseguir lucrar na transação, para melhor servir os interêsses nacionais (31).

\section{Dentro dêste espírito}

"mandou fazer no Departamento de Santa Cruz, o mais fértil da região, uma distribuiçâo eqüitativa das terras para os que a desejassem cultivá-las" (32).

Apesar disso a situação era precária, e simples decretos não podiam resolver os problemas:

"Os que me escrevem, diz S. E., não exageram a situação da Venczuela e dizem a verdade; mas se eqüivocam crendo que com uma ordem ou decreto posso remediar aquêles males. O que se necessita são medidas legislativas, um sistema de Fazenda que eu não tenho a faculdade de dar; a Convenção que tem êsse poder não o dará tampouco, porque não quer ordem senão a desordem, não quer a prosperidade da Naç̃o e sim sua ruína e desorganização. No entanto, farei para que se ordene uma reunião dos interessados numa junta e investigue as causas do mal e proponha o remédio" (33).

Se de um lado êle criticava a obra legislativa da Convenção, onde os interêsses particularistas e regionais predominavam acima dos interêsses continentais, tal crítica jamais levou o caudilho a posições de caráter totalitário no sentido ditatorial.

"Estava apenas a meia hora com o Comandante Montifar - escreve Peru de Lacroix $n_{0}$ Diário de Bucamaranga - quando entrou no meu quarto o Coronel Bolivar noticiando que ocorreu um movimento popular em Bogotá em 13 de junho; dai saiu um documento, declarando desconhecer a autoridajde da Convenção e sua obra, nomeando-me ditador" (34).

Bolivar no entanto, estava firmemente convicto que

"a ditadura era necessária ou mesmo indispensável quando um inimigo poderoso e cruel ocupava a maior

(31). - Dbidem, p. 60 .

(32): - Ibidem, p. 131 .

(33). - DIARIO, em 6 de junho de 1828.

(34). - Ibidem, p. 180,18 de junho de 1828 . 
parte do território e que para torná-lo independente, era preciso utilizar tôda fôrça e recursos que o país era capaz. Mas, conseguida a independência, livre o solo colombiano dos inimigos externos não quer êle - $\mathrm{O}$ Libertador - que cidadãos sejam regidos por um govêrno ditatorial e sim por um poder executivo constitucional" (35) .

Tal desêjo de respeito à vontade popular, de reafirmação de valores democráticos opostos ao carismatismo ditatorial por parte de Bolivar, reafirmam sua formação democrático-liberal e ao mesmo tempo a precariedade das críticas a êle dirigidas por estudiosos conspícuos, como por exemplo Salvador de Madariaga, sôbre quem já nos manifestamos na parte relativa a consideraçốes gerais, no início do presente trabalho.

O chefe da oposição a Bolivar, Dr. Mariano Alvarez, entre outras coisas salientava a respeito do liberalismo bolivariano:

“Assegurei também à Vossa Excelência que não via no semblante de nenhum dos deputados a menor divergência da alta e respeitável pessoa de V. Excia. Creio firmemente que os votos são unânimes e partem de um mesmo princípio, pelo imortal herói que com seus triunfos consolidou a independência do Perú e de tôda América e deu à pátria milhôes de homens. Seria uma imperdoável ingratidão se alguém com sua conduta desmentisse sentimentos tão gerais. $O$ único que divide as opiniōes è a classe de funções que se lhe irá investir: uns querem que seja conforme as leis, outros a ditadura sob a mesma ou com outra denominação. Meus sentimentos, em particular, são conforme os de Vossa Exceldncia, conforme tem repetidamente se manifestado contra todo poder absoluto, já se vê que isso é conforme à Ilustração ou chamar-se-á a mania do presente século" (36) .

Nessas afirmações encontramos o mais formal desmentido à pretensa veleidade ditatorial de Bolivar em atos ou idéias, êle como um homem que forjou suas idéias na luta, sabia perfeitamente que numa América atrasada, analfabeta, dispersa en $x$ luta contra uma potência como Espanha a ditadura transitòriamente serviria para a centralização dos esforços pẹla libertação. Mas daí nenhum passo avante. Após a libertação as franqüias democráticas, os valores liberais se colocavam na ordem do dia, a legitimidade popular do poder era indispensável para a ação política, isso de acôrdo com os ensinamentos da Ilustração e do utilitarismo inglês (Bentham).

A tal ponto era firme sua convicção liberal que êle escreve

(35). - Ibidem, pp. 181-182.

(36). 一 O'LEARY, ob. cit., p. 24. 
"antes de concluir, disse a V. Excia., com tôda a sinceridade que minha ansiedade de devolver a autoridade que exerço, me impõe a resolução de convocar o Congresso antes da época determinada pela lei, sem determe nos graves inconvenientes que os representantes indicaram, inspirado pelos clamores de minha pátria desêjo ansiosamente voltar à Colômbia" (37) .

Há um outro aspecto a considerar na formação do pensamento político bolivariano, o problema da monarquia, pois há estudiosas que o colocam perfunctòriamente como um adepto da monarquia querendo com êsse denominador comum generalizar sua completa personalidade política. Como dizíamos no início, Bolivar não é um ideólogo, é um homem que não usa a arma da crítica sem antes usar a crítica das armas, dentro dessa visão "existencial" as categorias políticas, democracia, república, monarquia, têm uma conotação bem diferente na aplicação de Bolivar à realidade americana do que os compêndios geralmente atribuem.

A êsse respeito êle escreve:

"Nenhum principe estrangeiro aceitaria por patrimônio um principado anarquista e sem garantias; as dívidas nacionais e a pobreza do país não permitem a existência de uma Côrte, senão miseràvelmente, as classes inferiores se alarmariam temendo os efeitos da aristocracia da desigualdade; os generais ambiciosos não suportariam a idéia de se verem privados do comando supremo; a nova notreza necessária e indispensável numa monarquia sairia da massa do povo com todos os ciúmes de um lado e o orgulho de outro lado. Ninguém teria paciência para agüentar essa miserável aristocracia coberta de pobreza, ignorância e animada de ridiculas pretensóes" (38).

$\mathrm{Na}$ época a Inglaterra era a única que podia fundar monarquias constitucionais.

No entanto sua influência foi predominantemente mais comercial do que política. Assim Lord Aberdeen anunciava em 1829 que seu govêrno não permitiria o estabelecimento de um príncipe inglês ou francês, nem de alguma outra dinastia européia na Colômbia. Ela aceita sòmente um príncipe espanhol ou a monarquia com o próprio Bolivar.

Como vimos, Bolivar, fiel à sua formação liberal, recusou-se não sòmente a ser ditador eleito como monarca constitucionalizado.

\footnotetext{
(37). - O'LEARY, ob. cit., pp. 218-219, in Resposta ao Conselho do Govêrno.

(38). - F. GARCIA CALDERON, Les democraties latines d'Amerique, Ed. Flammarion, 1914.
} 


\section{Congresso do Panamá.}

Realizou-se em 7 de dezembro de 1824 com plenipotenciários nomeados pela Colômbia, México, Rio da Prata, Chile, Guatemala. Esse Congresso tem um papel fundamental na caracterização do pensamento político bolivariano: a idéia da união continental das Américas opostas ao domínio do outro lado do Atlântico, em suma, o ideal panamericano. Esse Congresso cuidaria da formação de uma liga das nações americanas que seriam independentes, unidas por uma lei comum nas relações exteriores com um Congresso geral e permanente: O Brasil e os Estados Unidos foram convidados para o mesmo.

"Aspirara (Bolivar) com todo o ardor de sua alma fogosa reunir com laços mais estreitos numa Grande Confederação as repúblicas que encampou e fazer aparecer as criações de seus triunfos, segundo sua própria expressão. Não como nações, senão como irmãs unidas indissolùvelmente por todos os laços que as ligavam antes, com a única diferença que então estavam submetidas $\dot{a}$ um só tirano e que agora deviam gozar da mesma liberdade sob governos diferentes com cada povo em posse de sua soberania e livre segundo sua consciêntia" (39).

\section{Mesmo assim}

“considerava necessário formar uma só nação da América Meridional (naquela época significava tôdas as colônias hispano-americanas) para que um só govêrno pudesse aplicar os recursos de paises tão ricos a seu desenvolvimento e cultura" (40).

No Congresso do Panamá, Bolivar que pretendeu congregar a Bolívia, Perú, México e América Central, contou com grande oposição dos escravocratas norte-americanos:

"Os escravocratas dos Estados Unidos foram os mais veementes inimigos do Congresso, devido êle contemplar com bons olhos a emancipação de Cuba e Pôrto Rico, o que determinaria a abolição da escravidão com dano para seus interêsses. Temiam ademais que a Inglaterra pudesse influir numa Cuba e Pôrto Rico verdadeiramente livres" (41).

Rodeado de desconfiança pela Santa Aliança, perto de Cuba onde a Espanha preparava suas legiões, o Congresso do Panamá (1826) frustrou-se porque não abriu caminhos concretos, só valendo do ponto de vista moral, como um exemplo.

(39). - O'LEARY, ob. cit., p. 59.

(40). - Prólogo de V. LECUNA, ob. cit., p. 17.

(41). - L. A. SANCHEZ, Historia de America, p. 173. 
A respeito, as preocupações básicas de Bolivar se concentravam em: um govêrno constitucional que tivesse suficiente estabilidade para evitar dois erros - a anarquia ou a ditadura caudilhesca. Em segundo lugar, a União Pan-Americana para opor-se aos desígnios apetitosos da Europa e seu imperialismo:

“criar essa União, aliá-la aos Estados Unidos fundados por George Washington, cuja politica deve unir-se à nossa e opor-se juntas como insuperável barreira à ambição da Europa” (42) .

O pensamento bolivariano é fundamentalmente baseado no espírito de pan-americanismo, no intento de união de uma América dividida por interêsses econômicos ie políticos europeus, seccionadas em repúblicas autárquicas, quando elementos culturais, lingüísticos e econômicos comuns criam a necessidade do pan-americanismo como forma política para as Américas Central e do Sul.

\section{Conclusão.}

O universo de idéias políticas de Simon Bolivar é criado na base da ação, politica e militar, que configura seu perfil ideológico.

Pertencente à raça dos homens que forjam sua visão do universo partindo dos dados da experiência, como Robespierre, Lincoln ou Cavour, êle se vale das idéias políticas para realização de objetivos vitais.

A Carta de Jamaica (1815), o Congresso Constitucional de Angostura (1829), o Congresso do Panamá (1826), cristalizam a ação e pensamento político bolivariano na construção de uma Constituição liberal - democrática conforme os princípios da Ilustração adaptados à realidade latino-americana; o sonho de uma América Unida, com a realização đo Congresso do Panamá; as divisões subsequientes das Américas em Estados Nacionais que permitem a incursão do capitalismo europeu, as friç̧ões entre êsses Estados problemas como da Banda Oriental, Guerra do Chaco, mostram no sentido negativo, a profunda visão bolivariana de uma América unida em tôrno de princípios pan-americanos, acima de regionalismos e cisões que na realidade só servem para fragmentar o continente, atiçando as ambições de imperialismos da mais variada espécie que se dirigem cobiçosos para a América.

Bolivar, apesar de juízos contraditórios a seu respeito, permaneceu a vida tôda fiel àquêles princípios que nortearam seu chamado à guerra sem tréguas ao invasor espanhol, suas vitórias de Pichincha e Ayacucho, seu projeto de Constituição da Bolívia, o Congresso do Panamá, dessa ação resulta um princípio básico: à

(42). - V. LECUNA, prólogo, ob. cit,, p. 17. 
liberdade das Américas liga-se indissolìvelmente a solidariedade continental em princípios de igualdade democrática.

A grande lição de Bolivar foi que a independência latino-americana depende de sua unidade em tôrno de princípios comuns, se - continente não quiser servir de palco a lutas de interêsses estranhos: como por exemplo, o sucedido com a Guerra do Chaco.

A vida política de Bolivar transcorreu im moto sostenido, isso quer dizer, por tôda sua obra atravessa o halo de um espírito livre, intransigente nos princípios e fins, com capacidade de amalgamar os mais diferentes povos em função de objetivos comuns. Como Sucre, O'Higgyns, Bolivar jamais se caracterizou por um maníaco do poder. Nesta época em que a tomada do poder político assume proporções dramáticas com os diversos totalitarismos dominantes, o exemplo de Bolivar recusando a ditadura que lhe ofereciam é um símbolo de um homem de uma grandeza pessoal e histórica dificilmente comparável por seus congêneres.

Homem de ação por natureza e inclinação, gênio militar de Pichincha, de Ayacucho, estadista da Constituição Boliviana e do Congresso do Panamá, numa época em que vemos ascender ao poder mediocridades douradas que são uma edição piorada dos "condottieri" renascentistas com a única virtú, o aperfeiçoamento das técnicas totalitárias de contrôle do poder - êle constitui um exemplo, um ensinamento e um símbolo para as Américas.

MAURICIO TRAGTENBERG. 